\title{
Normal ranges of biorbital and interorbital distances in healthy Turkish pregnancies at 19-23 weeks of gestation and correlation with craniofacial structures
}

\author{
Halil Gürsoy Pala, Burcu Artunç-Ülkümen, Faik Mümtaz Koyuncu, Yıldız Uyar, Yeşim Bülbül-Baytur \\ Department of Obstetrics and Gynecology, Division of Perinatology, Celal Bayar University Faculty of Medicine, \\ Manisa, Turkey
}

\section{Abstract}

Objective: We aimed to determine the normal ranges for biorbital (BOD) and interorbital distances (IOD) during the second trimester in Turkish women with normal pregnancies and to assess the correlation between BOD, IOD, and other fetal craniofacial structures and biometric parameters.

Material and Methods: Our retrospective study comprised 1328 women with singleton normal pregnancies who had undergone ultrasonography (USG) examinations at 19-23 weeks of gestation in the second trimester screening. The measurements of BOD and IOD were obtained with the coronal section of the fetal face at the plane of orbits.

Results: Mean BOD was $3.4 \pm 0.33 \mathrm{~cm}$, whereas mean IOD was $1.28 \pm 0.24 \mathrm{~cm}$. Correlation analysis revealed that BOD was significantly correlated with IOD, transcerebellar diameter (TCD), cisterna manga (CM), nuchal fold (NF), nasal bone (NB), biparietal diameter (BPD), head circumference (HC), abdominal circumference (AC), femur length (FL), and gestational week. There was a significant relation between IOD and the lateral ventricle posterior horn, TCD, CM, NF, NB, BPD, HC, AC, and FL.

Conclusion: The reference ranges obtained in our study enabled accurate evaluation of BOD and IOD in the second trimester of normal pregnancies. USG detection of fetal orbital biometric anomalies may alert the clinician for different anomalies associated with abnormal development of eye. (J Turk Ger Gynecol Assoc 2015; 16: 170-3)

Keywords: Biorbital distance, interorbital distance, mid-trimester scan, Turkish population

Received: 31 March, 2015

Accepted: 19 April, 2015

Available Online Date: 14 July, 2015

\section{Introduction}

The anomalies of the fetal face, including orbits, can be detected on ultrasonography (USG) (1). On USG, the orbitas appear as hypoechoic circles in the skull of fetus with the echogenic circle of the lens within it. USG can be used to measure the biorbital distance (BOD) and interorbital distance (IOD) in particular (2). Furthermore, these values can be useful for the estimation of gestational age. Prenatal evaluation of fetal orbit growth is superior for the early assessment of some facial and cranial abnormalities (3, 4). Moreover, many morphological parameters that are revealed on USG in the second trimester of pregnancy are reported to be associated with genetic abnormalities $(5,6)$. The ocular biometric parameters can be helpful in detecting anomalies involving the fetal orbital development that can be indicative of aneuploidy and various anomalies (7).

The growth and improvement of the face are associated to the forebrain development (8). Therefore, the defects of the cerebral and face are usually related to each other (7), and the biometry of the orbits could be a practical USG value for early assessment of some abnormalities related to the maldevelopment of the fetal orbits.

The aim of second trimester USG scan is to obtain exact diagnostic knowledge for optimized perinatal management with best possible results for fetus and mother. This protocol is used to conclude the age of gestation and obtain the measurements of fetus to determine the growth anomalies in late pregnancy (9).

Therefore, the objectives of our study were to determine normal ranges of BOD and IOD at 19-23 weeks of gestation in Turkish women with normal pregnancies and to assess the correlation between BOD, IOD, and other fetal craniofacial structures and biometric parameters.

\section{Material and Methods}

This retrospective study comprised 1328 women with singleton pregnancies who had undergone USG examinations between May 2013 and September 2014 at our perinatology outpatient clinic at 19-23 weeks of gestation for the second trimester screening. All the pregnant women provided their 

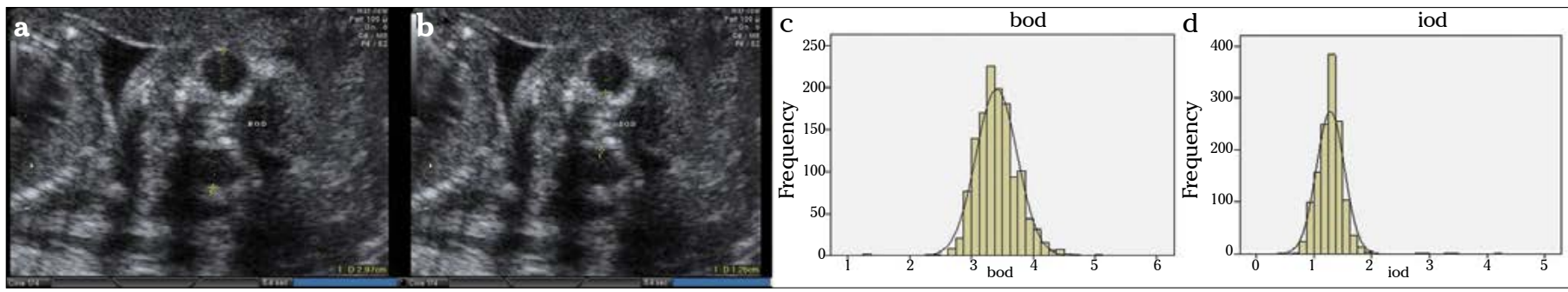

Figure 1. a-d. Measurement of biorbital distance (BOD) in coronal plane (a), Measurement of interorbital distance (IOD) in coronal plane (b), Distribution of BOD values of healthy fetuses in second trimester (c), Distribution of IOD values of healthy fetuses in second trimester (X-axis: BOD and IOD values) (Y-axis: Frequencies) (d)

Table 1. Demographic and ultrasonographic features of the study

\begin{tabular}{|l|c|c|c|c|}
\hline n: 1328 & Mean & $\begin{array}{l}\text { Standard } \\
\text { deviation }\end{array}$ & Minimum & Maximum \\
\hline Age & 28.07 & 5.61 & 17 & 43 \\
\hline Gestational week & 20.48 & 2.24 & 19 & 23 \\
\hline $\begin{array}{l}\text { Lateral ventricle } \\
\text { posterior horn (mm) }\end{array}$ & 4.7 & 2.04 & 2.82 & 9.77 \\
\hline Cisterna magna (mm) & 4.08 & 1.7 & 2.22 & 9.07 \\
\hline Nuchal fold (mm) & 4.93 & 3.8 & 2.4 & 5.9 \\
\hline Nasal bone (mm) & 4.85 & 1.08 & 2.81 & 6.4 \\
\hline $\begin{array}{l}\text { Transcerebellar } \\
\text { diameter (mm) }\end{array}$ & 22.04 & 2.73 & 19.04 & 25.35 \\
\hline $\begin{array}{l}\text { Biparietal diameter } \\
\text { (cm) }\end{array}$ & 5.19 & 0.5 & 3.97 & 5.98 \\
\hline $\begin{array}{l}\text { Head circumference } \\
\text { (cm) }\end{array}$ & 18.41 & 4.46 & 6.21 & 24.12 \\
\hline $\begin{array}{l}\text { Abdominal } \\
\text { circumference (cm) }\end{array}$ & 17.47 & 1.88 & 14.67 & 22.9 \\
\hline Femur length (cm) & 3.77 & 0.5 & 2.9 & 4.88 \\
\hline
\end{tabular}

informed consent for the second trimester scan. Women with multiple pregnancies; chronic systemic disease, such as vasculitis, connective tissue disorder, diabetes, and hepatic or renal failure; and pregnancies with fetal structural or chromosomal anomaly, preeclampsia, and intrauterine growth retardation were not included in the study. The age of gestation was calculated from the first day of the last menstruation and confirmed again by the USG crown-rump length value of the first trimester. The maternal age and parity were also recorded. The local institutional ethics committee approved our study.

Ultrasound exams were performed with a GE Voluson 730-Pro system and a RAB 3.5 MHz array abdominal probe (GE Medical Systems, Milwaukee, WI). All examinations were performed with the use of a transabdominal probe by two operators who had completed the internet-based course on antenatal surveillance and were also accredited with the "Certificate of Competence" by Fetal Medicine Foundation. Examinations were conducted by one of the operators, while the other operator was independently observing the measurements. Head circumference (HC), biparietal diameter (BPD), abdominal circumference (AC), and femur length (FL) were measured for fetal biometry.
As a part of the mid-trimester, BOD and IOD were measured in all fetuses. The measurements of BOD and IOD were obtained with the coronal section of the fetal face at the plane of orbits in which the USG image was symmetrical with the two eye balls of largest and equal diameter (4). The orientation of the probe was re-adapted during successive viewing till the optimal sight of the orbits was possible. BOD is clarified as the distance between the lateral borders of two orbits (Figure 1a); IOD is clarified as the distance between the medial borders of two orbits (Figure 1b) (4). Freeze-frame USG functions and electronic calipers were set for the measurements of orbitas. BOD and IOD were measured three times, the mean value was obtained, and orbital measurements at gestational age were also recorded (10).

Transcerebellar diameter (TCD), cisterna magna (CM), and nuchal fold (NF) were measured on the transcerebellar plane. Lateral ventricle posterior horn (VP) was measured on the transventricular plane. Nasal bone (NB) was measured on the median sagittal facial profile plane.

Statistical analysis was performed with SPSS v.20 (SPSS Inc., Chicago, Illinois, United States). The results of the study were expressed as mean \pm standard deviation. Spearmen's correlation analysis was used to investigate the association between BOD, IOD, and other parameters. A p value $<0.05$ was considered to be statistically significant.

\section{Results}

In this study, 1328 scans at $19-23$ weeks of gestation were included. Mean maternal age was $28.07 \pm 5.61$, while mean gestational age was $20.48 \pm 2.24$ weeks. Mean BOD was $3.4 \pm 0.33$ $\mathrm{cm}$, while mean IOD was $1.28 \pm 0.24 \mathrm{~cm}$. The distribution of BOD and IOD values of healthy fetuses in the second trimester is shown in Figure 1c, d. The demographic and ultrasonographic features of the study are shown in Table 1.

Correlation analysis revealed that BOD was significantly correlated with IOD $(r=0.395, \mathrm{p}<0.001)$, TCD $(\mathrm{r}=0.404, \mathrm{p}<0.001)$, $\mathrm{CM}(\mathrm{r}=0.181, \mathrm{p}<0.001), \mathrm{NF}(\mathrm{r}=0.226, \mathrm{p}<0.001), \mathrm{NB}(\mathrm{r}=0.879$, $\mathrm{p}<0.001)$, BPD $(\mathrm{r}=0.816, \mathrm{p}<0.001), \mathrm{HC}(\mathrm{r}=0.844, \mathrm{p}<0.001)$, $\mathrm{AC}(\mathrm{r}=0.857, \mathrm{p}<0.001), \mathrm{FL}(\mathrm{r}=0.816, \mathrm{p}<0.001)$, and gestational week $(\mathrm{r}=0.558, \mathrm{p}=0.002)$. There was significant relation between IOD and Vp $(r=0.116, p<0.001)$, TCD $(r=0.966$, $\mathrm{p}<0.001), \mathrm{CM}(\mathrm{r}=0.065, \mathrm{p}=0.03), \mathrm{NF}(\mathrm{r}=0.538, \mathrm{p}<0.001), \mathrm{NB}$ $(\mathrm{r}=0.884, \mathrm{p}<0.001)$, BPD $(\mathrm{r}=0.569, \mathrm{p}=0.002), \mathrm{HC}(\mathrm{r}=0.527$, $\mathrm{p}=0.005)$, AC $(r=0.609, p=0.001)$, and FL $(r=0.516, p=0.006)$. Correlation analysis is shown in Table 2. 
Table 2. Correlation analysis of biorbital and interorbital distances with other second trimester craniofacial structures and fetal biometry parameters

\begin{tabular}{|l|c|c|c|c|}
\hline & \multicolumn{2}{|c|}{ Biorbital distance } & \multicolumn{2}{c|}{ Interorbital distance } \\
\hline & $\mathbf{r}$ & $\mathbf{p}$ & $\mathbf{r}$ & $\mathbf{p}$ \\
\hline TCD & 0.404 & $<0.001$ & 0.966 & $<0.001$ \\
\hline NF & 0.226 & $<0.001$ & 0.538 & $<0.001$ \\
\hline NB & 0.879 & $<0.001$ & 0.884 & $<0.001$ \\
\hline Gestational week & 0.558 & 0.002 & 0.267 & 0.1 \\
\hline BPD & 0.816 & $<0.001$ & 0.569 & 0.002 \\
\hline HC & 0.844 & $<0.001$ & 0.527 & 0.005 \\
\hline AC & 0.857 & $<0.001$ & 0.609 & 0.001 \\
\hline FL & 0.816 & $<0.001$ & 0.516 & 0.006 \\
\hline
\end{tabular}

$\mathrm{p}<0.05$ was significant

TCD: transcerebellar diameter; NF: nuchal fold; NB: nasal bone;

BPD: biparietal diameter; HC: head circumference; AC: abdominal circumference; FL: femur length

\section{Discussion}

When performing a second trimester USG scan, the evaluation of the face is believed to be an important feature of fetal anatomic survey (9). It is useful in diagnosing associated brain abnormalities, (7) and is also associated for a genetic syndrome (11). Birnholz et al. (12) examined a relation between delayed cerebral development and reduced ocular growth. We examined highly significant correlation between IOD and BOD with craniofacial measurements. Our study results confirm previous hypotheses regarding the association between the growth of the eyes and facial and brain structures. Therefore, the reference ranges for fetal BOD and IOD that we determined appear to reflect the expected fetal development and adds valuable knowledge regarding the growth and development of the brain and facial structures.

In this study, we used the coronal section to measure BOD and IOD because the lateral edges of BOD and IOD could be better defined in coronal section than in the transverse section. The determination of the reference ranges for fetal BOD and IOD may prove to be important in allowing detection of hypo and hypertelorism. Abnormal BOD and IOD measurements could be associated with a broad range of detectable anomalies (13). The most common abnormalities are cleft lip-palate, facial asymmetry, agenesis of corpus callosum, holoprosencephaly, craniosynostosis, microcephaly, macrocephaly, and chromosome anomalies, such as trisomy 21,18 , and 13 , and triploidy (14). BOD and IOD may be used to evaluate the normal growth and development of the eye and as a complementary device in the elaboration of different anomalies associated to cranial and facial malformations.

$\mathrm{BPD}, \mathrm{HC}, \mathrm{AC}$, and FL have been used to evaluate fetal biometry. Moreover, there are several studies regarding fetal eye biometry (15). Jeanty et al. (16) studied the normal fetal orbital biometry. Previous growth charts for the fetal eye have mainly focused on the bony distances (10-12). It is critical to determine the normal values of eye growth during the second trimester of normal gestations. Our study revealed that in a Turkish population, gestational age is significantly correlated to biorbital diameter. This data may be helpful in pregnancies at risk for chromosomal disorders, which include fetal orbital abnormalities. Further studies are required to determine whether these measurements, alone or in combination with other ultrasonographic cranial or facial values, prove to be a useful device to screen fetuses for genetic diseases.

The main limitations of this study were the retrospective single center design and the lack of the postnatal long term outcomes. The advantage of our study was the large sample size for statistical significance. Future multi-center prospective studies with postnatal long term outcomes may be determined with the use of BOD and IOD alone or in combination with other ultrasonographic measurements for chromosomal abnormality screening. In conclusion, to the best of our knowledge, this study is first to demonstrate normal ranges of BOD and IOD during the second trimester in a healthy Turkish population. The orbital diameter measurement results of our study may contribute as reference values of our population for further studies. Fetal orbital biometric anomalies may be accompanied with other structural anomalies. Furthermore, a normal second trimester USG scan cannot absolutely exclude abnormal development of the orbitas because some of the ocular defects are detected during the late periods of pregnancy.

Ethics Committee Approval: Ethics committee approval was received for this study from the Local Institutional ethics committee of Celal Bayar University.

Informed Consent: Written informed consent was obtained from patients who participated in this study.

Peer-review: Externally peer-reviewed.

Author Contributions: Concept - H.G.P., B.A.U.; Design - H.G.P., B.A.U., Y.B.B.; Supervision - Y.B.B.; Resource - H.G.P., B.A.U., F.M.K., Y.U., Y.B.B.; Materials - H.G.P., B.A.U., F.M.K., Y.U., Y.B.B.; Data Collection and/ or Processing - H.G.P., B.A.U.; Analysis and/or Interpretation - H.G.P., B.A.U.; Literature Search - H.G.P.; Writing - H.G.P., B.A.U.; Critical Reviews - F.M.K., Y.U., Y.B.B.

Conflict of Interest: No conflict of interest was declared by the authors.

Financial Disclosure: The authors declared that this study has received no financial support.

\section{References}

1. Dilmen G, Koktener A, Turhan NO, Tez S. Growth of the fetal lens and orbit. Int J Gynaecol Obstet 2002; 76: 267-71. [CrossRef]

2. Goldstein I, Tamir A, Zimmer EZ, Itskovitz-Eldor J. Growth of the fetal orbit and lens in normal pregnancies. Ultrasound Obstet Gynecol 1998; 12: 175-9. [CrossRef]

3. Achiron R, Gottlieb Z, Yaron Y, Gabbay M, Gabbay U, Lipitz S, Mashiach $\mathrm{S}$. The development of the fetal eye: In utero ultrasonographic measurements of the vitreous and lens. Prenat Diagn 1995; 15: 155-60. [CrossRef]

4. Bronshtein M, Zimmer E, Gershoni-Baruch R, Yoffe N, Meyer H, Blumenfeld Z. First- and second-trimester diagnosis of fetal ocular defects and associated anomalies: Report of eight cases. Obstet Gynecol 1991; 77: 443-9. 
5. $\quad$ Shipp TD, Benacerraf BR. Second trimester ultrasound screening for chromosomal abnormalities. Prenat Diagn 2002; 22: 296-307. [CrossRef]

6. Nyberg DA, Souter VL. Sonographic markers of fetal trisomies: second trimester. J Ultrasound Med 2001; 20: 655-74.

7. Monteagudo A, Timor-Tritsch IE. Fetal face and central nervous system. In: Jaffe R, Bui T-H (edts). Textbook of Fetal Ultrasound. New York: The Parthenon Publishing Group; 1998. p. 103.

8. Cohen MM, Jirasek JE, Guzman RT, Gorlin RJ, Peterson MQ. Holoprosencephaly and facial dismorphia: nosology, etiology and pathogenesis. Birth Defects Orig Artic Ser 1971; 7: 125-35.

9. Salomon LJ, Alfirevic Z, Berghella V, Bilardo C, Hernandez-Andrade E, Johnsen SL, et al. Practice guidelines for performance of the routine mid-trimester fetal ultrasound scan. Ultrasound Obstet Gynecol. 2011; 37: 116-26. [CrossRef]

10. Mayden KL, Tortora M, Berkowitz RL, Bracken M, Hobbins JC. Orbital diameters: a new parameter for prenatal diagnosis and dating. Am J Obstet Gynecol 1982; 144: 289-97.
11. Babcook CJ. The fetal face and neck. In Ultrasonography in Obstetrics and Gynecology, Callen PW (edts). WB Saunders Co.: Philadelphia; 2000. p. 307.

12. Birnholz JC. Ultrasonic fetal ophthalmology. Early Hum Dev 1985; 12: 199-209. [CrossRef]

13. Rosati P, Guariglia L. Early transvaginal fetal orbital measurements: a screening tool for aneuploidy? J Ultrasound Med 2003; 22: 1201-5.

14. Kivilevitch Z, Salomon LJ, Benoit B, Achiron R. Fetal interlens distance: normal values during pregnancy. Ultrasound Obstet Gynecol 2010; 36: 186-90. [CrossRef]

15. Sukonpan K, Phupong V. A biometric study of the fetal orbit and lens in normal pregnancies. J Clin Ultrasound 2009; 37: 69-74. [CrossRef]

16. Jeanty P, Dramaix-Wilmet M, Van Gansbeke D, Van Regemorter N, Rodesch F. Fetal ocular biometry by ultrasound. Radiology 1982; 143: 513-6. [CrossRef] 